\title{
Effect of feed restriction on the environmental variability of birth weight in divergently selected lines of mice
}

\author{
Nora Formoso-Rafferty ${ }^{1}$, Isabel Cervantes ${ }^{1 *}$, Juan Pablo Sánchez ${ }^{2}$, Juan Pablo Gutiérrez ${ }^{1}$ and Loys Bodin ${ }^{3}$
}

\begin{abstract}
Background: Selection of mice for decreased environmental variability of birth weight has achieved higher survivability and larger litter size as a correlated response to canalized selection, which suggests higher welfare and robustness, and animals that are more homogeneous. However, in these studies, animals were not exposed to an environmental challenge. To demonstrate the advantages of this mouse line with a low environmental variability of birth weight, animals from two divergent lines (high and low variability of birth weight) were subjected to feed restriction. The objective of this study was to use these divergent lines to compare their response in terms of robustness against an environmental challenge. At weaning, 120 females, i.e. four full-sib females from 10 random litters of three consecutive generations of selection, were chosen from these divergent lines. The total number of females was divided into four groups, which were subjected to a feeding regimen by imposing different levels of feed restriction (i.e. 75 , 90 and $85 \%$ of full ad libitum feed across three generations, respectively) in different combinations during the growth and reproduction periods.

Results: Animals from the "low" line were less sensitive to a change in feed level than those from the "high" line. Regarding reproduction, the "low" line performed better in terms of number of females having parturitions, number of parturitions, and litter size. Imposing a feed restriction on female mice during their growth period did not affect the birth weight of their pups. The "low" line was preferred because of its higher reproductive efficiency and survival under an environmental challenge.
\end{abstract}

Conclusions: Selection for decreased environmental variability of birth weight produces animals that are less sensitive to environmental conditions, which can be interpreted as having greater robustness.

\section{Background}

Animal production requires the effective use of resources, i.e. animals that perform better and that are more robust. Moreover, sustainability is related to robustness, and robustness is related to homogeneity, but evaluating robustness and homogeneity in an experimental population has rarely been carried out [1]. Mormede and Terenina [2] suggested that robustness is the

\footnotetext{
*Correspondence: icervantes@vet.ucm.es

${ }^{1}$ Departamento de Producción Animal, Facultad de Veterinaria,

Universidad Complutense de Madrid, Madrid, Spain

Full list of author information is available at the end of the article
}

combination of a high production potential with a low sensitivity to environmental changes or to a certain level of stress.

Since several decades, feed costs represent the major part of breeding costs and are one of the major concerns for breeders. Different feeding strategies, such as feeding to appetite (ad libitum) or feeding under restrictions, are common practices in commercial animal production [3]. Efficient use of feed resources for growing animals is one of the major factors that influence the economic sustainability of animal production [4].

Selection for homogeneity, in general, can affect feed efficiency and may benefit productivity and animal welfare, even when feed restrictions are applied. However, feed restriction can affect both animal performance 
and welfare. In rabbits, it has been demonstrated that an ad libitum diet maximizes performance [5] increases sexual receptivity, ovulation rate, blastocyst size, and implantation rate [6].

Previously a divergent selection experiment was carried out for 17 generations in two mouse lines to gain more insight into the effect of selection for homogeneity of birth weight (BW) [7]. The study of these two ad libitum fed lines by Formoso-Rafferty et al. [1] included the evaluation of production, reproduction, and animal welfare traits. They showed that feed efficiency was similar in both lines, but that fertility and welfare were higher in the homogeneous line, which suggested higher robustness.

Previously, some authors reported that homogeneity of body weight was correlated with important reproductive traits such as fertility or litter size in rabbits [8-10] and with robustness traits such as welfare [2] or survival in piglets and rabbits [11-13]. However, in these studies, the animals were not exposed to any environmental challenges, which did not allow direct assessment of the change in performance under new environmental conditions. Animals with a performance that remains unchanged under an environment challenge can be considered as being more robust. Hence, the objective of our study was to analyze the influence of feed restriction, which is considered an environmental challenge, in two mouse lines that were divergently selected for environmental variability of birth weight (BW).

\section{Methods}

Data were recorded on two mouse lines that were divergently selected for environmental variability of BW. Details of the selection process are in Formoso-Rafferty et al. [14]. In the current paper, "low" and "high" will be used for the line with, respectively, a low and high environmental variability of BW. Briefly, this selection experiment demonstrated a divergent response for the residual variance of BW and that it was positively correlated with traits related to welfare and robustness.

Data for animals from three consecutive generations of the selection experiment (12, 13 and 14) were available. Hence, 40 females (four full-sib females from 10 random litters) per generation and line were chosen at weaning, divided into four treatment groups ( 1 full-sib per group) that were assigned different combinations of feed restriction during the growth and reproduction stages.

First, the 40 females per line were divided into two groups (20 females per group), with one group fed ad libitum and the other with a restricted diet during the growth period (GP). The effect of the feeding regime during the GP was noted as R_GP. Female body weight in $\mathrm{g}$ (W) was recorded weekly from weaning to 3-11 weeks of age. Starting at 11 weeks of age, both groups were fed ad libitum (recovery period) until the start of the reproduction period (RP).

To explore the effects of line and feeding regime (ad libitum or feed-restricted) on feed efficiency during the GP, the cumulated transformation index was computed for each of the 10 weeks after weaning as the ratio of cumulative feed intake (in $g$ from weaning to the specific week) and weight gain (in $g$ from weaning to the specific week). The last 2 weeks of this 10 -week period were a recovery period during which all animals were fed ad libitum.

One week before mating, each GP feeding group was divided into two new groups (Fig. 1): one was fed ad libitum and the other with a restricted feed regimen during the RP. Thus, the resulting four groups had a combination of ad libitum and restricted feeding regimes during GP and RP (Fig. 1). The effect of the feeding regime during the $R P$ was identified as $R \_R P$.

During the RP, each female cohabitated with one male from the same line for two reproduction cycles to give the female the opportunity to become pregnant twice. Pregnant females were checked daily, litter size was recorded within $24 \mathrm{~h}$ after birth, and the new-borns were weighed and identified individually. The number of females with only one (P1) or two (P2) parturitions were also recorded. $\mathrm{P} 1$ was recorded on all 40 females that were available within line and generation, while P2 was recorded only on the females that had a P1. An overall measurement of fertility (\%) was also recorded within line, generation, and feeding regime, as the percentage of available females that had a parturition. In generation 12, survival (\%) was also measured as the percentage of females alive compared to the total number at the start of the experiment.

At the beginning of the experiment, in generation 12 , and taking the current literature concerning feeding restriction on mice and other species [15-20] into account, we decided to apply a feeding restriction of $75 \%$ of the full ad libitum intake. The amount of feed provided to the restricted groups was $75 \%$ of the mean ad libitum consumption in the corresponding line at a particular physiological state (GP or RP) in the three previous generations [1]. Unexpectedly, $75 \%$ of ad libitum feeding resulted in increased mortality, particularly in the high line, which suggests that animals from this line were less robust. Because of this unexpected mortality, we decided to reduce the percentage of restriction in the subsequent generations, i.e. in the second generation (13), feeding restriction was modified to $90 \%$ of the ad libitum intake. In this particular case, some animals did not consume all the food provided, which strictly speaking means that the feeding regimen was not restricted. Thus, in the third generation (14), we applied a feeding restriction of $85 \%$. 


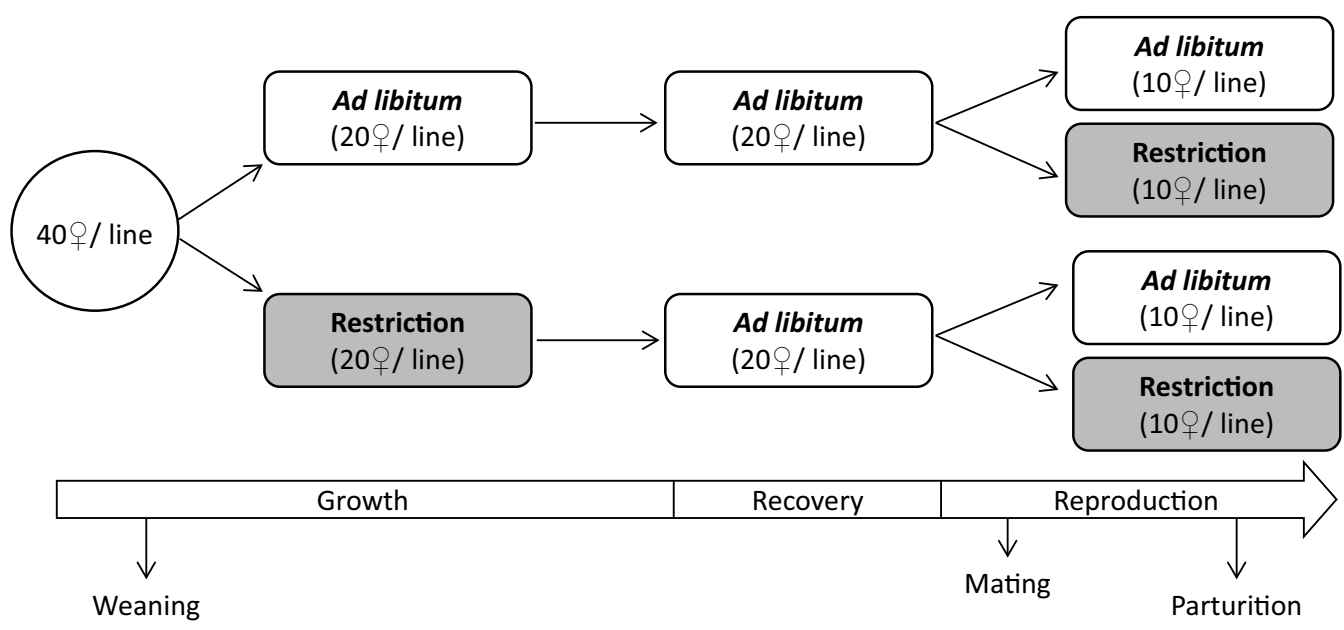

Fig. 1 Design of the post-weaning experiment and distribution of the females in the corresponding experimental group according to their feeding regimen (ad libitum or restricted) during growth and reproduction periods

\section{Statistical model for female growth and fertility}

The data used in this study included weekly weights for each female from weaning to 10 weeks of age, with an initial 240 records and a final count of 225 at the end of the experiment. The weights for each week were analyzed with a model that included the effects of R-GP (ad libitum or feed-restricted), line (low or high), generation $(12,13$ or 14$)$, the litter size in which the female was born (with 3 levels, i.e. from 4 to 9,10 to 11 and 12 to 15 pups), and the first order interactions between line, generation, and R_GP. It would have been better to include also a genetic effect to separate the influence of selection from the environmental effect of the generation, but this was not possible because of the small number of animals in the dataset. The analysis was carried out with the Release 4.1 ASReml program [21]. Survival and fertility were compared based on single statistical Chi square tests using the FREQ procedure of the SAS software [22].

\section{Statistical model for birth weight of offspring}

The dataset contained 1275 records for BW of the progeny of 116 females with at least one parturition, 158 litters, and 4900 pedigree records. The heteroscedastic model of SanCristobal-Gaudy et al. [23] was fitted to the BW data. This model assumes that the BW mean and its residual variance are both affected by genetic and environmental factors and can be written as:

$$
y=\mu+m+l+e^{(\eta+v / 2)} \varepsilon,
$$

where $\mu$ and $\eta$ represent the systematic effects that affect the mean and environmental variability of BW, respectively, $m$ and $v$ are random effects that account for the maternal genetic effects that affect the mean and variability of BW, respectively, and $l$, is a random litter effect with variance $\sigma_{l}^{2}$.

Vectors $\mathbf{m}$ and $\mathbf{v}$ of the genetic values were assumed to follow a joint distribution:

$$
\left(\begin{array}{c}
\mathbf{m} \\
\mathbf{v}
\end{array}\right) \sim N\left[0,\left(\begin{array}{cc}
\sigma_{m}^{2} & \rho \sigma_{m} \sigma_{v} \\
\rho \sigma_{m} \sigma_{v} & \sigma_{v}^{2}
\end{array}\right) \otimes \mathbf{A}\right],
$$

where $\otimes$ denotes the Kronecker product and $\mathbf{A}$ is the additive genetic relationship matrix between animals.

Regarding the systematic effects, the model included the feeding regimen of the dam during the growth (R_GP) and reproduction (R_RP) periods (ad libitum or feed-restricted), line (low or high), generation (12, 13, or 14), the litter size (LS) that each dam was born in (LS: from 4 to 9,10 to 11 and 12 to 15 pups; i.e. 3 levels), parturition number (P1 or P2), litter size of the progeny $\left(\mathrm{LS}_{\text {pup }}\right.$ : from 1 to 5,6 , from 7 to 9,10 , and from 11 to 13 pups; i.e. 5 levels), and the sex of the progeny (male, female, or unknown), along with the first order interactions between line, generation, and RP. A first analysis included all of these effects in the model but, in a second step, those that were not significant $(p<0.05)$ were removed. Only the results obtained from this second analysis are presented.

The pedigree information went up to the founding population of both lines and, thus, we could assess the genetic influence of line on BW by considering differences in the means of breeding value predictions for the animals involved in the experiment, which means that the systematic effect of line explains exclusively the environmental effects associated with line. 
The heteroscedastic model was solved through a double hierarchical generalized linear model (DHGLM) developed by Felleki et al. [24] within the frame of ASReml (ASReml Release 4.1 software) [21]. Since this model assumes a residual variance for each level of combination of systematic effects [7], when required, the estimate of the residual variance for a given level of a given effect was obtained by averaging over the solutions of all other effects as:

$$
\hat{\sigma}_{e_{s l}}^{2}=e^{i=1, \sum_{s y s t e m a t i c s}^{i \neq 1}\left(\sum_{j=1, n_{s}} \frac{\hat{b}_{i j}}{n_{s}}\right)}+\hat{b}_{s l},
$$

where $\hat{b}_{i j}$ is the solution for a particular level $l$ of a systematic effect $s$, and $n_{s}$ is the number of levels of the systematic effect. In particular, the estimate of the residual variance for the combined effect of line and RP was obtained as:

$$
\hat{\sigma}_{e_{s l}}^{2}=e^{\overline{s e x}+\overline{L S \text { pup }}+\overline{P N}+\overline{\text { generation } * R P}+\overline{G P * R P}+\text { line } * R P_{i}} .
$$

\section{Results}

\section{Growth and fertility}

Table 1 shows the differences in survival between lines and feed intake regimens at 10 weeks of age and at

Table 1 Female survival rate (\%) during growth at 10 weeks of age and at mating in both the high and low environmental variability of BW lines, with ad libitum feeding or under feed restriction, in the first generation of the experiment

\begin{tabular}{llcc}
\hline Line & Age & Ad libitum feed & Feed restriction \\
\hline High & 10 weeks & $100^{\mathrm{a}}$ & $65^{\mathrm{bd}}$ \\
& Mating & $95^{\mathrm{a}}$ & $60^{\mathrm{bd}}$ \\
Low & 10 weeks & 100 & $95^{\mathrm{c}}$ \\
& Mating & 100 & $85^{\mathrm{c}}$ \\
\hline
\end{tabular}

a Versus b: significant differences within feeding regimen

c Versus d: significant differences within lines mating in generation 12 of the experiment, in which the feeding restriction was $75 \%$ of full ad libitum. At 10 weeks of age and at mating, there were significant differences in survival between feeding regimes (ad libitum or feed-restricted) in the high line, and between lines in the restricted feeding regimen.

Regarding W, Table 2 shows the significance level of the factors considered in the model at week 0 (at weaning), 1 , $2,3,4,5,6$, or 7 after weaning. There was no significant environmental influence of the line on any of the weights analyzed. The generation effect on W was highly significant $(p<0.001)$ at 2 weeks after weaning and later on. The effect of litter size on $\mathrm{W}$ was also highly significant $(p<0.001)$ throughout the experiment (weeks 0-7). As expected, the feeding regime (R_GP) showed a highly significant effect on $\mathrm{W}(p<0.001)$ for all weeks after weaning (weeks 1-7).

The interaction between line and generation was either not or weakly $(p<0.01)$ significant across the growth period, but the interaction between generation and R_GP was highly significant $(p<0.001$ or $p<0.01)$, reflecting differences in the level of restriction applied in each generation. In fact, all first-order interactions for $\mathrm{W}$ were significant to some extent at some weeks. The significance of the interaction between line and R_GP on W was also high $(p<0.001$ or $p<0.01)$ from weeks 2 to 7 , which indicates that the impact of feed restriction differed between the two lines.

Figure 2 shows the least square means for $\mathrm{W}$ at 4 weeks after weaning in both lines in the three generations analyzed. Week 4 was taken as a reference for the adult age of a mouse, but the pattern was similar for all weeks throughout the experiment. Irrespective of diet (ad libitum or restricted), females from the low line were slightly lighter than those from the high line and females that were fed ad libitum in the low line maintained a similar weight over all three generations, in contrast to those of the high line.

Table 2 Significance of weekly female weights between lines, generations, feeding regimen during the growth period

\begin{tabular}{|c|c|c|c|c|c|c|c|c|}
\hline & $w_{0}$ & $w_{1}$ & $W_{2}$ & $W_{3}$ & $W_{4}$ & $W_{5}$ & $W_{6}$ & $W_{7}$ \\
\hline Line & ns & ns & ns & ns & ns & ns & ns & ns \\
\hline Generation & ns & ns & $* * *$ & $* * *$ & $* * *$ & $* * *$ & $* * *$ & $* * *$ \\
\hline R_GP & - & $* * *$ & $* * *$ & $* * *$ & $* * *$ & $* * *$ & $* * *$ & $* * *$ \\
\hline Line* generation & $* *$ & ns & ns & ns & $* *$ & ns & ns & ns \\
\hline Generation*R_GP & - & $* *$ & $* * *$ & $* * *$ & $* * *$ & $* * *$ & $* * *$ & $* * *$ \\
\hline Line $^{*}$ R_GP & - & ns & $* * *$ & $* * *$ & $* * *$ & $* *$ & $* * *$ & $* *$ \\
\hline LS & $* * *$ & $* * *$ & $* *$ & $* * *$ & $* * *$ & $* * *$ & $* * *$ & $* * *$ \\
\hline
\end{tabular}
(R_GP), their interactions and litter size

Ww live weight (g) (in week $w$ after weaning as a subindex), LS litter size, - effect not taken into account, $n$ s not significant

${ }^{* *} p<0.01$; *** $p<0.001$ 


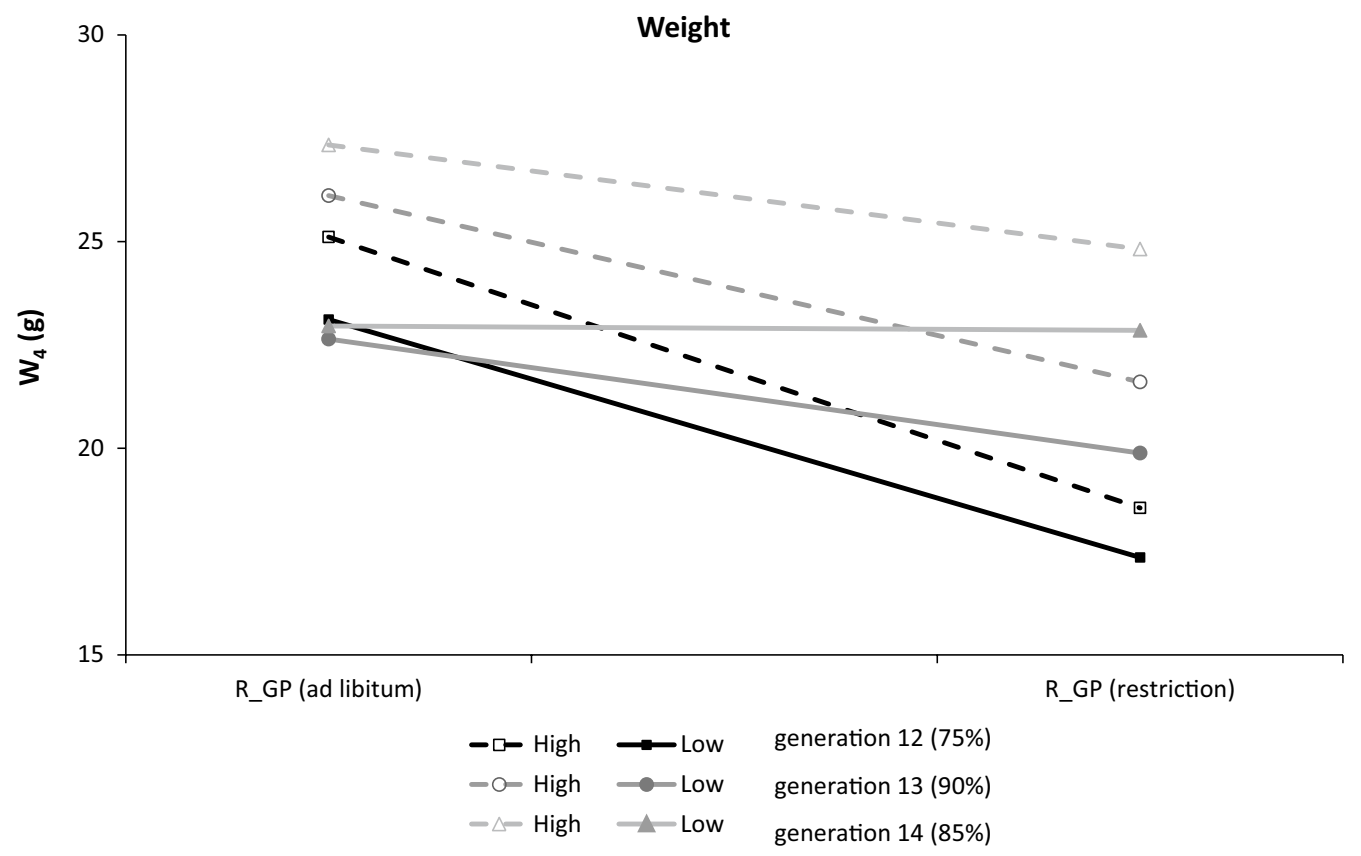

Fig. 2 The least square mean estimates of female weight (in $\mathrm{g}$ ) in the fourth week after weaning in the low line (continuous lines) and high line (discontinuous lines) depending on feeding regimen (ad libitum or restricted) in the three generations

Figure 3a, b show the evolution of female weight (Fig. 3a) and of the cumulated transformation index (Fig. 3b) for each line and feeding regime from 0 to 10 weeks after weaning. The effect of feed restriction was similar in both lines but animals from the low line recovered their normal body weight in one or 2 weeks after being put back on the ad libitum feeding regimen, whereas those from the high line continued to have a slightly smaller body weight than individuals from the same line that were permanently fed ad libitum (Fig. 3a). The cumulated transformation index was similar for both lines regardless of the feeding regimen. After a short recovery period, females that had been subjected to feed restriction reached a lower (better) transformation index value than females that were never feed-restricted, in both lines (Fig. 3b). This compensatory growth effect could be interesting for application to livestock.

Table 3 shows the significance levels for the effects of generation, line and feeding regimen in the growth and reproduction periods, as well as their first order interactions, on fertility (\%) in both parturitions (P1 or P2). The effect of line was highly significant $(p<0.001)$ for both parturitions. The other effects were more important in P2 than $\mathrm{P} 1$, except in generation 12 , in which a stronger feed restriction was applied.

The raw data for overall fertility (\%) for each combination of line, generation, and feeding regimen during reproductive and growing periods are in Table 4 for P1 and P2. The statistical test refers to differences in feeding regimen. Fertility of animals from the low line was higher than that of animals from the high line. Concerning feeding regimen, feed-restricted females performed worse than those fed ad libitum, except at P1 for high line females of generation 14 that were feed-restricted during the reproduction period. Table 4 also shows that the negative influence of feeding restriction on fertility was stronger when it was applied during the reproduction period than during the growth period, thus reducing the percentage of animals that had a P2. When the restriction was applied during the reproduction period, the number of P2 differed significantly between lines. Feed restriction seemed to affect animals from the high line more, regardless of the physiological stage, growth or reproduction, but these differences were not significant.

\section{Birth weight of offspring}

Table 5 shows the significance of the systematic effects and the estimated variances of the random effects for the mean and the variability of BW. The genetic correlation between the location and dispersion parameters for $\mathrm{BW}$ was 0.34 , but the standard error of this estimate was very large due to the numerous factors of variation and to the limited amount of data.

Regarding the effect of feed restriction in dams on the BW of their offspring, the effect of offspring generation was significant only for the offspring of mothers that 

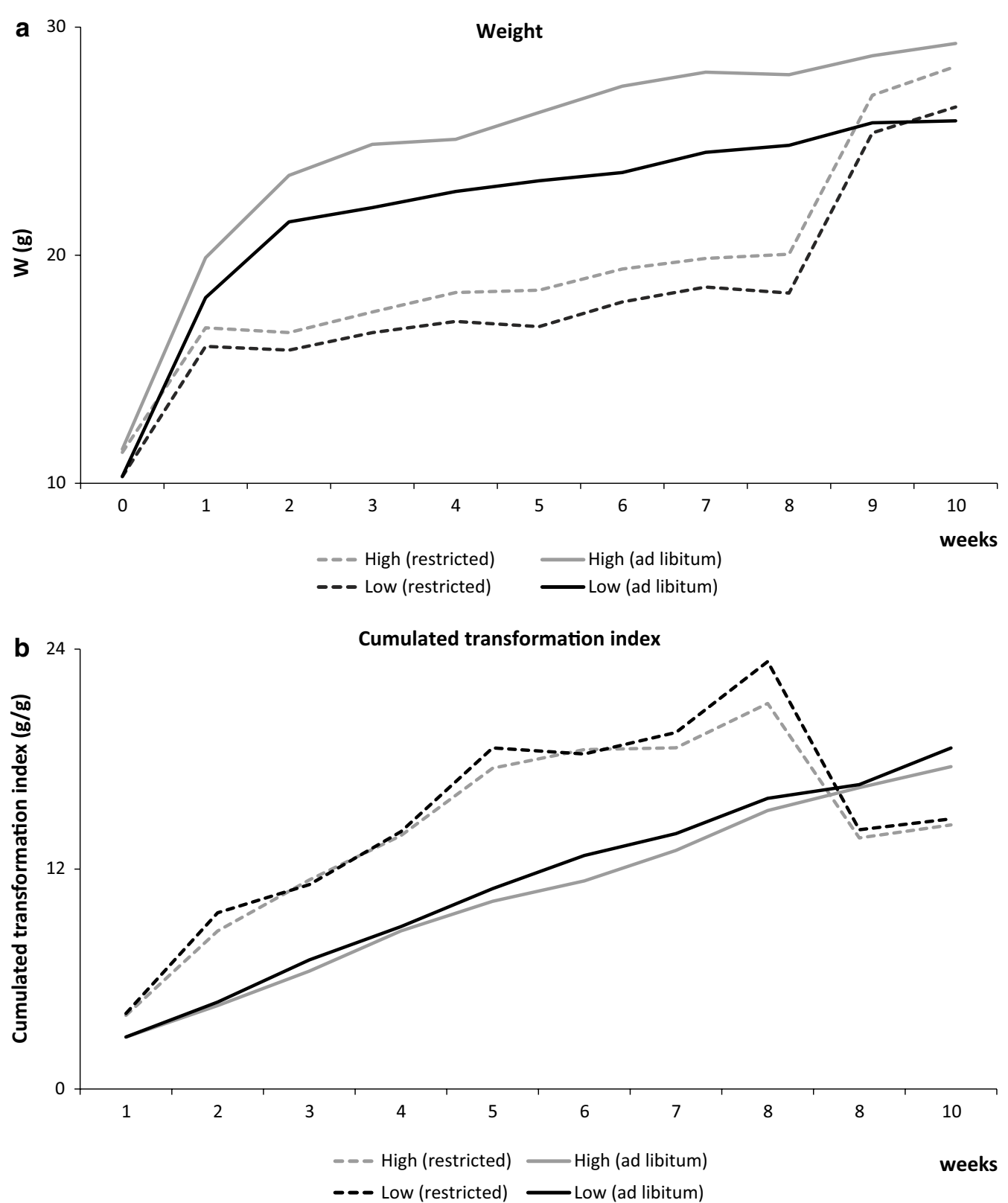

Fig. 3 Phenotypic evolution of the female weekly weight (in g) (a) and the cumulated transformation index (b) depending on feeding regimen (ad libitum or restricted) in both lines with high and low environmental variability of BW from weaning to 10 weeks later

were feed-restricted during the growth period. For these feed-restricted dams, the BW of their pups decreased as the level of feed restriction of the dams increased (Fig. 4a). Similarly, as shown in Fig. 4b, the effect of feed restriction of the mothers during their growth did not affect the BW of their pups, when they were fed ad libitum during the reproduction period. Nevertheless, when the females were feed-restricted during the reproduction period, pups from the females that were fed ad libitum during their growth had a slightly higher BW, than those had been feed-restricted during the same period.

Among the effects that influence the variability of $\mathrm{BW}$, only sex and the interaction between line and feeding regime during the reproduction period were significant (Table 5). This interaction led to different residual variances between the combinations of line and feeding regimens during reproduction, as shown in Table 6, with corresponding estimates of residual variances in Fig. 5. 
Table 3 Significance between lines, feeding regimen (ad libitum or restricted) during the growth period (R_GP) and the reproduction period (R_RP), generation (gen) and its first order interactions for the number of females having one (P1) and two (P2) parturitions

\begin{tabular}{|c|c|c|c|c|c|c|c|c|}
\hline & \multicolumn{4}{|l|}{ P1 } & \multicolumn{4}{|l|}{ P2 } \\
\hline & \multirow[t]{2}{*}{ Total } & \multicolumn{3}{|c|}{ Generation } & \multirow[t]{2}{*}{ Total } & \multicolumn{3}{|c|}{ Generation } \\
\hline & & $12_{(75 \%)}$ & $13_{(90 \%)}$ & $1_{(85 \%)}$ & & $12_{(75 \%)}$ & $13_{(90 \%)}$ & $14_{(85 \%}$ \\
\hline Line & $* * *$ & $* *$ & $* *$ & ns & $* * *$ & $* * *$ & $* *$ & $*$ \\
\hline R_GP & $*$ & $* *$ & ns & ns & ns & ns & $*$ & ns \\
\hline R_RP & ns & $* * *$ & ns & ns & $* * *$ & $* * *$ & $* * *$ & $*$ \\
\hline Line*R_GP & ns & ns & ns & ns & ns & ns & ns & ns \\
\hline Line*R_RP & ns & ns & ns & ns & $* * *$ & $* *$ & $* * *$ & ns \\
\hline R_GP*R_RP & ns & ns & ns & ns & $* *$ & ns & $* *$ & ns \\
\hline Gen & * & & & & $*$ & & & \\
\hline Gen*line & ns & & & & ns & & & \\
\hline Gen*R_GP & $*$ & & & & ns & & & \\
\hline Gen*R_RP & $* * *$ & & & & $* *$ & & & \\
\hline
\end{tabular}

ns not significant

${ }^{*} p<0.05 ;{ }^{* *} p<0.01 ;{ }^{* * *} p<0.001$

Table 4 Fertility rate (\%) according to feeding regimen (ad libitum or feed restriction) during the growth period (R_GP) and the reproduction period ( $R \_R P$ ) in mouse lines with high and low environmental variability of BW

\begin{tabular}{|c|c|c|c|c|c|c|c|c|c|c|}
\hline \multirow[t]{2}{*}{ Period } & \multirow[t]{2}{*}{ Generation } & \multirow[t]{2}{*}{ Feeding regimen } & \multicolumn{4}{|l|}{ High line } & \multicolumn{4}{|l|}{ Low line } \\
\hline & & & First birth & $p$ & Second birth & $p$ & First birth & $p$ & Second birth & $p$ \\
\hline \multirow[t]{6}{*}{ R_GP } & $12_{(75 \%)}$ & Ad libitum & 70 & ** & 10 & ns & 90 & ns & 45 & ns \\
\hline & & Restriction & 35 & & 10 & & 65 & & 30 & \\
\hline & $13_{(90 \%)}$ & Ad libitum & 80 & ns & 25 & ns & 95 & ns & 45 & ns \\
\hline & & Restriction & 55 & & 10 & & 95 & & 30 & \\
\hline & $14_{(85 \%)}$ & Ad libitum & 65 & ns & 0 & ns & 85 & ns & 20 & ns \\
\hline & & Restriction & 80 & & 10 & & 80 & & 25 & \\
\hline \multirow[t]{6}{*}{$R \_R P$} & $12_{(75 \%)}$ & Ad libitum & 80 & $* * *$ & 20 & $*$ & 90 & ns & 70 & $* * *$ \\
\hline & & Restriction & 25 & & 0 & & 65 & & 5 & \\
\hline & $13_{(90 \%)}$ & Ad libitum & 60 & ns & 30 & $*$ & 100 & ns & 75 & $* * *$ \\
\hline & & Restriction & 75 & & 5 & & 90 & & 0 & \\
\hline & $14_{(85 \%)}$ & Ad libitum & 65 & ns & 10 & ns & 80 & ns & 35 & ns \\
\hline & & Restriction & 80 & & 0 & & 85 & & 10 & \\
\hline
\end{tabular}

ns not significant

${ }^{*} p<0.05 ;{ }^{* *} p<0.01 ;{ }^{* * *} p<0.001$

Note that from the ad libitum to the restricted feeding regimen, the residual variance decreased more in the high line (18\%) than in the low line (5\%).

\section{Discussion}

We hypothesized that the effect of a feed restriction challenge would be stronger in the line selected for a high than for a low environmental variability of BW, which could be interpreted as the low line being more robust. Although our analysis was on mice that were divergently selected for variability of BW, this could reflect the advantages of selection for decreased variability of a particular trait on robustness and animal welfare in livestock production. Although there is no agreement in the definition of robustness, Knap [25] defines it as the capacity of achieving a high level of productive potential and supporting, at the same time, a certain level of stress, or expressing high productive level in different environments. Mormede and Terenina [2] expressed the same idea in a different way by suggesting that it is 
Table 5 Significance of the systematic effects and estimated variances of the random effects affecting both the mean BW $(\mu)$ and the environmental variability (v) and its genetic correlations ( $\rho)$

\begin{tabular}{llll}
\hline & BW $(\boldsymbol{\mu})$ & BW $(\boldsymbol{v})$ & $\boldsymbol{\rho}$ \\
\hline Sex & $* * *$ & $* * *$ & \\
LS $_{\text {pup }}$ & $* * *$ & & \\
PN & $*$ & & \\
Gen*R_RP & ${ }^{* * *}$ & & \\
R_GP*R_RP & ns & ns & \\
Line*R_RP & & & $0.34(0.33)$ \\
$\sigma_{l}^{2}$ & $0.0198(0.0028)$ & $0.0454(0.0163)$ & \\
$\sigma_{m}^{2}$ & $0.0061(0.0029)$ &
\end{tabular}

$L S_{\text {pup }}$ litter size, $P N$ parturition number, gen generation, $R_{-} G P$ growth period, $R \_R P$ reproduction period, $\sigma_{I}^{2}$ litter variance, $\sigma_{m}^{2}$ maternal genetic variance, $n s$ no significant

${ }^{*} p<0.05 ;{ }^{* * *} p<0.001$

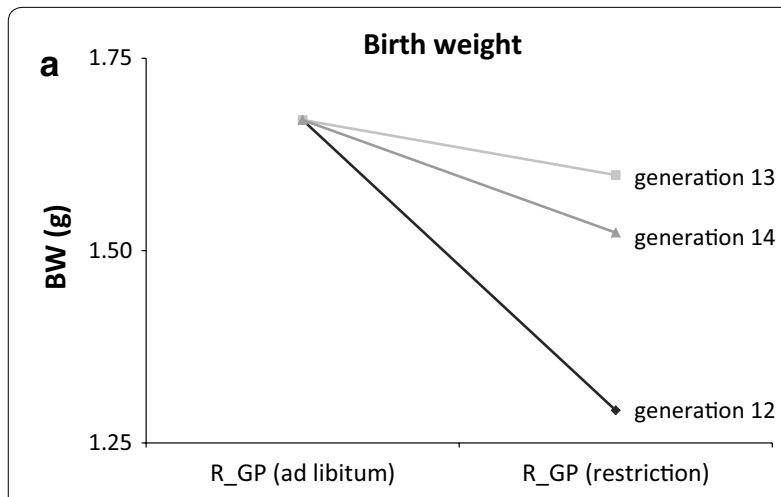

b

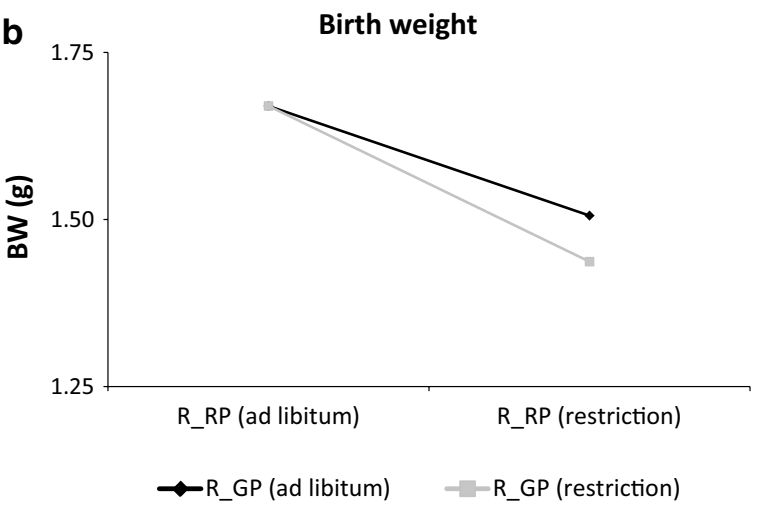

Fig. 4 Birth weight of pups (BW) depending on the feeding regimen (ad libitum or restricted) of the dam during the growth period (R_GP) (a) and the reproduction period (R_RP) (b) in the three generations

a combination of a high production potential with a low sensitivity towards environmental changes.

Formoso-Rafferty et al. [1] showed that animals from the low line were more robust and expressed higher animal welfare and reproductive performance. They mentioned the need to study whether homogeneity could also be desirable under environmental challenges. Thus, the aim of our research was to study the relationship between homogeneity and robustness in a stressful environment. We tried to achieve this by assessing the relationships that exists between a very important production feature, i.e. feed efficiency and homogeneity and robustness. Silalahi et al. [26] argued that animals selected for high production efficiency might be more susceptible to behavioral, physiological, or immunological problems, thus making them less robust [27-29].

In the present experiment, the level of feed restriction had to be modified at each generation, because of unexpected and undesired observations in the initial generations. Thus, we applied a feeding regimen that consisted of 75,90 , and $85 \%$ of ad libitum intake in the first, second, and third generations of the experiment, respectively. As a result, the effects of feed-restriction were expected to differ between generations, with a stronger effect in the first generation. However, even in these last two generations, the feed-restrictions applied were expected to generate the desired challenged environment. Although in the design used here, the effect of feed-restriction level could be influenced partly by other causes associated with generation and selection effects, we assumed that the observed differences between generations were mainly due to feed-restriction levels.

\section{Growth and fertility}

The results show that, although the two lines did not statistically differ in weight after weaning, there was a significant interaction between line and feeding regime during the growth period (Table 2). This interaction, which was observed from week 2 after weaning, could be interpreted as a consequence of a cumulated negative effect from the previous weeks. Figure 2 shows the least square means of the weights in week 4 after weaning, at which time animals had reached maturity (i.e. at 49 days of age [30]). Although there were differences in body weight between the lines, they were not significant (Table 2); animals from the low line were lighter than those from the high line within feeding regimen and generation, as shown in Fig. 2. The smaller weight of animals from the low line under ad libitum feeding had already been reported based on a larger number of animals [1, 31]. The differences between animals fed ad libitum and feed-restricted were always higher for the high than for the low line. Thus, our results suggest that animals from the low line are less sensitive to a change in feed level than those from the high line.

In some cases, a low level of feed-restriction can have a beneficial effect. Young mammals [18] are prone to 
Table 6 Solutions of the interaction between line and feeding regimen (ad libitum or restricted) during the reproduction period (R_RP) effect for the environmental variability $\left(\eta_{\text {line } * R \_R P}\right)$ and corresponding residual variance $\left(\sigma^{2}\right)$

\begin{tabular}{llll}
\hline Line & Feeding regimen & $\boldsymbol{\eta}_{\text {line*R_RP }}$ & $\boldsymbol{\sigma}^{\mathbf{2}}=\boldsymbol{e}^{\boldsymbol{\eta}}$ \\
\hline High & Ad libitum & -3.61 & 0.027 \\
& Restricted & -3.78 & 0.023 \\
\multirow{2}{*}{ Low } & Ad libitum & -3.77 & 0.025 \\
& Restricted & -3.82 & 0.022 \\
\hline
\end{tabular}

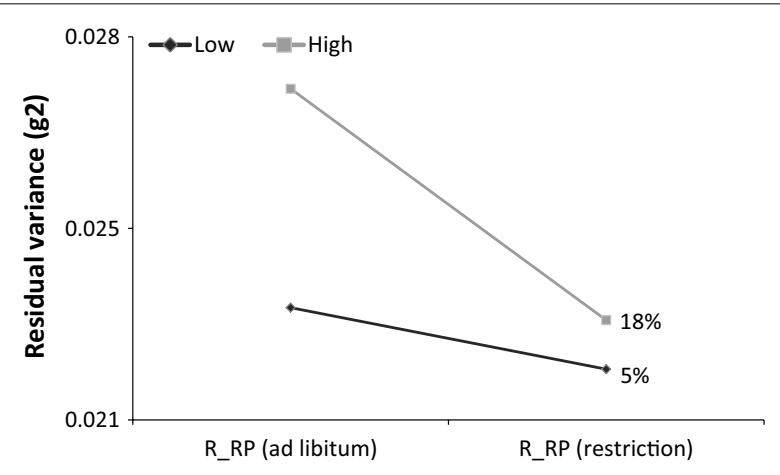

Fig. 5 Drop in residual variance $\left(\sigma_{e_{s}}^{2}\right)$ in the lines with low and high environmental variability of BW depending on feeding regimen (ad libitum or restricted) during the reproduction period (R_GP)

digestive diseases, particularly around the weaning period. Feeding practices such as restricted feeding are known to affect physiological and productive traits in growing rabbits $[18,19,32]$. Lu et al. [33] reported that, after returning to ad libitum feeding, feed-restricted animals can show compensatory growth [34, 35], increased nutrient digestibility [16, 36], and increased feed conversion rate [37]. This compensatory growth depends on the duration, level, and pattern of feed restriction $[16,17,36$, 38]. The effect of feed-restriction on growth was more easily compensated for, when the duration of feed restriction was short or moderate. We observed that the high line was more negatively affected by a greater level of feed restriction than the low line. Although feed restriction affected the growth of both lines similarly, animals from the low line recovered their normal weight in one or 2 weeks, whereas those from the high line did not attain a normal weight at the end of the experiment (Fig. 3a). Nevertheless, it is generally assumed that a very low level of feed restriction could prevent animals from fattening, and this effect seemed to be more beneficial for the high than the low line since feed restriction increased reproductive performance in the high line and not to the same extent in the low line.

\section{Birth weight of offspring}

The effect of feed restriction during the reproduction period was greater for females that had also been feedrestricted during their growth period, thus manifesting a memory effect. However, we would not have observed this differential effect of feed restriction during the reproduction period, if the experiment had been designed to feed-restrict animals only during the growth period. In spite of the recovery capacity of females, the low effect on the BW of their own pups made the memory effect patent, confirming previously reported results in rats [39] and cattle [40].

The estimate of the variance of the litter effect was threefold greater than the genetic variance of the maternal effect, which was small but different from zero. This result is in agreement with that previously reported during the selection process [14].

Overall, selection for decreased environmental variability of BW appeared to have conferred a lower sensitivity of the mothers to the changing environmental conditions. Animals from the high line were more sensitive to harsh feeding restrictions than those from the low line. However, a moderate feeding restriction prevented the high line females from fattening, resulting in fertility rates that were comparable between lines, as shown in generation 14 (Table 4).

The estimate of the genetic correlation between the mean and dispersion parameters for BW was 0.34 (Table 5), which is similar to that obtained by FormosoRafferty et al. [7] on the same population but with a higher accuracy. Because of this correlation, the mean BW of the offspring was greater for the high line than for the low line, as shown by Formoso-Rafferty et al. [7].

The genetic component of the environmental variance can be related to the capacity of animals to adapt to new environmental conditions, which can affect their welfare [41]. There is some evidence that environmental variability is under genetic control [7]. In addition to the parameters estimated in several datasets [7], two selection experiments that used variability of BW as a selection criterion were performed with success, one in mice [14] and one in rabbits [13].

Feed costs represent the largest financial input in livestock production systems but can be reduced by reducing feed intake [42, 43]. However, limiting feed intake is also expected to reduce production and, therefore, livestock must be selected based on feed efficiency rather than only on feed intake [44]. Based on our findings, animals that show less environmental variability of BW are more robust, which means that they cope better with the environmental challenge of feed restriction.

Blasco et al. [43] demonstrated that a rabbit line selected for homogeneity in litter size tolerated external 
stressors more effectively than the line selected for heterogeneity in litter size. Thus, in general, animals selected for increased environmental variability appear to be more sensitive to stress, have a lower immune response to infections, and a higher hepatic activity [45]. These effects have consequences on disease resistance but also on animal welfare, because animals that cope more effectively with their environment have better welfare than animals that are more sensitive. Using the definition by Mormede and Terenina [2] and the conclusions in Formoso-Rafferty et al. [1], our findings demonstrate a relationship between low environmental variability and robustness in a challenging environment. We also show that the low line has a higher survival rate and better fertility even when the animals were feed-restricted. Finally, the low line is more stable and better able to tolerate stressful conditions.

The mouse is frequently used as a model animal in selection experiments because of its favorable characteristics such as short generation intervals and large number of pups per parturition. Conclusions based on mice can be extrapolated to livestock species such as pigs or rabbits [46]. A research project on homogeneity in sheep is in progress in which the selection index has been modified to include a specific weight for this selection objective [47]. More research is needed to ensure the suitability of applying this type of selection in cattle.

\section{Conclusions}

When an environmental challenge in the form of a feed restriction was applied, the mouse line selected for a low environmental variance of BW had a higher survival rate and better reproductive efficiency than the high line. The animals from the low line were less affected by the feed restriction and were more robust to this environmental challenge than those from the high line.

\section{Authors' contributions}

NFR, IC and JPG conceived and designed the experiment. NFR, IC, JPG, JPS and LB collaborated on data analyses and initial interpretations of the results. All authors contributed to the discussion and interpretations of the results. All authors read and approved the final manuscript.

\section{Funding}

This research was supported by the Feed-a-Gene Project funded by the European Union H2020 Program under Grant Agreement EU 633531 and the Instituto Nacional de Investigación y Tecnología Agraria y Alimentaria (INIA, Madrid, Spain) Project RTA2014-00015-C02-02.

\section{Availability of data and materials}

The datasets generated and/or analyzed during the current study are available from the corresponding author upon reasonable request.

\section{Ethics approval and consent to participate}

All experimental procedures were carried out at the animal facilities of the Complutense University of Madrid (UCM, Spain), which meet the requirements of the European Union for scientific procedure establishments, under the project license of the UCM Scientific Ethic Committee. Animal manipulations were performed in accordance with the Spanish Guidelines for Care and Use of Animals in Research (RD53/2013).

\section{Consent for publication}

Not applicable.

\section{Competing interests}

The authors declare that they have no competing interests.

\section{Author details}

${ }^{1}$ Departamento de Producción Animal, Facultad de Veterinaria, Universidad Complutense de Madrid, Madrid, Spain. ${ }^{2}$ Animal Breeding and Genetics Program, Institute for Food and Agriculture Research and Technology, Caldes de Montbui, Barcelona, Spain. ${ }^{3}$ Génétique, Physiologie et Systèmes d'Elevage, INRA, Castanet-Tolosan, Toulouse, France.

Received: 3 January 2019 Accepted: 5 June 2019

Published online: 13 June 2019

\section{References}

1. Formoso-Rafferty N, de la Flor M, Gutiérrez JP, Cervantes I. Feed and reproductive efficiency differences between divergently selected lines for birth weight environmental variability in mice. J Anim Breed Genet. 2018;135:378-89.

2. Mormede P, Terenina E. Molecular genetics of the adrenocortical axis and breeding for robustness. Domest Anim Endocrin. 2012:43:116-31.

3. Szendrô Z, Szendrő K, Zotte AD. Management of reproduction on small, medium and large rabbit farms: a review. Asian-Australasian. J Anim Sci. 2012;25:738-48.

4. Sánchez JP, Ragab M, Quintanilla R, Rothschild MF, Piles M. Genetic parameters and expected responses to selection for components of feed efficiency in a Duroc pig line. Genet Sel Evol. 2017;49:86.

5. Maertens L, Aerts JM, De Brabander DL. Effet d'un aliment riche en acides gras omega-3 sur les performances et la composition du lait des lapines et la viabilité de leur descendance. In: Proceedings of the 11 èmes Journées de la Recherche Cunicole: 29-30 November 2005, Paris; 2005.

6. Ashworth CJ, Toma LM, Hunter MG. Nutritional effects on oocyte and embryo development in mammals: implications for reproductive efficiency and environmental sustainability. Philos Trans R Soc Lond B Biol Sci. 2009;364:3351-61.

7. Formoso-Rafferty N, Cervantes I, Ibáñez-Escriche N, Gutiérrez JP. Modulating birth weight heritability in mice. J Anim Sci. 2017;95:531-7.

8. Bolet G, Garreau H, Joly T, Theau-Clement M, Falieres J, Hurtaud J, et al. Genetic homogenisation of birth weight in rabbits: indirect selection response for uterine horn characteristics. Livest Sci. 2007;111:28-32.

9. García ML, Argente MJ, Muelas R, Birlanga V, Blasco A. Effect of divergent selection for residual variance of litter size on health status and welfare. In: Proceedings of the 10th world rabbit congress: 3-6 September 2012. Sharm El-Sheikh; 2012.

10. Larzul C, Ducrocq V, Tudela F, Juin H, Garreau $H$. The length of productive life can be modified through selection: an experimental demonstration in the rabbit. J Anim Sci. 2014;92:2395-401.

11. Högberg A, Rydhmer L. A genetic study of piglet growth and survival. Acta Agric Scand A Anim Sci. 2000;50:300-3.

12. Damgaard LH, Rydhmer L, Lovendahl P, Grandinson K. Genetic parameters for within-litter variation in piglet birth weight and change in within-litter variation during suckling. J Anim Sci. 2003;81:604-10.

13. Garreau H, Bolet G, Larzul C, Robert-Granie C, Saleil G, San Cristobal M, et al. Results of four generations of a canalising selection for rabbit birth weight. Livest Sci. 2008;1 19:55-62.

14. Formoso-Rafferty N, Cervantes I, Ibáñez-Escriche N, Gutiérrez JP. Genetic control of the environmental variance for birth weight in seven generations of a divergent selection experiment in mice. J Anim Breed Genet. 2016;113:227-37

15. Xiccato G. Feeding and meat quality in rabbits: a review. World Rabbit Sci. $1999 ; 7: 75-86$. 
16. Di Meo C, Bovera F, Marono S, Vella N, Nizza A. Effect of feed restriction on performance and feed digestibility in rabbits. Ital J Anim Sci. 2007:6:765-7.

17. Gidenne T, Feugier A. Feed restriction strategy in the growing rabbit. 1. Impact on digestion, rate of passage and microbial activity. Animal. 2009;4:501-8.

18. Gidenne T, Combes S, Fortun-Lamothe L. Feed intake limitation strategies for the growing rabbit: effect on feeding behaviour, welfare, performance, digestive physiology and health: a review. Animal. 2012;6:1407-19.

19. Knudsen C, Combes S, Briens C, Coutelet G, Duperray J, Rebours G, et al. Increasing the digestibleenergy intake under a restriction strategy improves the feed conversion ratio of the growing rabbit without negatively impacting the health status. Livest Sci. 2014;169:96-105.

20. Birolo M, Trocino A, Zuffellato A, Xiccato G. Effect of feed restriction programs and slaughter age on digestive efficiency, growth performance and body composition of growing rabbits. Anim Feed Sci Technol. 2016;222:194-203.

21. Gilmour AR, Gogel BJ, Cullis BR, Welham SJ, Thompson R. Asreml user guide release 4.1 functional specification. Hemel Hempstead: VSN International Ltd; 2014.

22. SAS/STAT ${ }^{\circledR}$ User's Guide (Release 8.2). Cary: SAS Inst. Inc.; 1990.

23. SanCristobal-Gaudy M, Elsen JM, Bodin L, Chevalet C. Prediction of the response to a selection for canalisation of a continuous trait in animal breeding. Genet Sel Evol. 1998;30:423-51.

24. Felleki M, Lee D, Lee Y, Gilmour AR, Ronnegard L. Estimation of breeding values for mean and dispersion, their variance and correlation using double hierarchical generalized linear models. Genet Res (Camb). 2012;94:307-17.

25. Knap PW. Breeding robust pigs. Aust J Exp Agric. 2005;45:763-73.

26. Silalahi P, Tribout T, Prunier A, Billon Y, Gogué J, Bidanel JP. Estimation of the effects of selection on French Large White reproductive performance using frozen semen. J Anim Sci. 2016;94:3655-62.

27. Rauw WM, Gomez-Raya L. Genotype by environment interaction and breeding for robustness in livestock. Front Genet. 2015;6:310.

28. Phocas F, Bobe J, Bodin L, Charley B, Dourmad JY, Friggens NC, et al. More robust animals: a major challenge for sustainable development of livestock production implying the blossoming of fine and hight hroughput phenotyping. INRA Prod Anim. 2014;27:181-94.

29. Rauw WM, Kanis E, Noordhuizen-Stassen EN, Grommers FJ. Undesirable side effects of selection for high production efficiency in farm animals: a review. Livest Prod Sci. 1998;56:15-33.

30. Silver LM. Mouse genetics. Concepts and applications. New York: Oxford University Press; 1995.

31. Formoso-Rafferty N, Cervantes I, Ibáñez-Escriche N, Gutiérrez JP. Correlated genetic trends for production and welfare traits in a mouse population divergently selected for birth weight environmental variability. Animal. 2016:10:1770-7.

32. Read T, Combes S, Gidenne T, Destombes N, Grenet L, Fortun-Lamothe L. Stimulate feed intake before weaning and control intake after weaning to optimise health and growth performance. World Rabbit Sci. 2015;23:145-53.
33. Lu J, Shen Y, He Z, Dai X, Wang D, Zhang J, et al. Effects of a short-term feed restriction on growth performance, blood metabolites and hepatic igf-1 levels in growing rabbits. World Rabbit Sci. 2017;25:233-9.

34. Zotte $A D$, Remignon $\mathrm{H}$, Ouhayoun J. Effect of feed rationing during post-weaning growth on meat quality, muscle energy metabolism and fibre properties of Biceps femoris muscle in the rabbits. Meat Sci. 2005;70:301-6.

35. De Oliveira MC, da Silva RP, Araujo LS, da Silva VR, Bento EA, da Silva DM. Effect of feed restriction on performance of growing rabbits. Rev Bras Zootec. 2012:41:1463-7.

36. Abdel-Wareth AAA, Kehraus S, Ali AHH, Ismail ZS, Sudekum KH. Effects of temporary intensive feed restriction on performance, nutrient digestibility and carcass criteria of growing male Californian rabbits. Arch Anim Nutr. 2015;69:69-78.

37. Tůmová E, Skřivan M, Skřivanová V, Kacerivská L. Effect of early feed restriction on growth in broiler chickens, turkeys and rabbits. Czech J Anim Sci. 2002;47:418-28.

38. Romero C, Cuesta S, Astillero JR, Nicodemus N, De Blas C. Effect of early feed restriction on performance and health status in growing rabbits slaughtered at $2 \mathrm{~kg}$ live-weight. World Rabbit Sci. 2010;18:211-8.

39. Bisset DV, Zerquera AC, Fuentes MGB, Garcia MJR, CabralesVTG. Crecimiento y composición corporal de las crías de ratas sometidas a restricción alimentaria. Rev Cubana Invest Bioméd. 1999;18:104-10.

40. Frasinelli CA, Casagrande HJ, Veneciano JH. La condición corporal como herramienta de manejo en rodeos de cría bovina. San Luis: INTA- Estación Experimental Agropecuaria, Información Técnica. 2004;168:1-17.

41. Blasco A, Martínez-Álvaro M, García ML, Ibáñez-Escriche N, Argente MJ. Selection for environmental variance of litter size in rabbits. Genet Sel Evol. 2017:49:48.

42. Ferrell $\mathrm{CL}$, Jenkins TJ. Cow type and the nutritional environment: nutritional aspects. J Anim Sci. 1985:61:725-41.

43. Noblet J, Shi XS, Dubois S. Metabolic utilization of dietary energy and nutrients for maintenance energy requirements in sows: basis for a net energy system. Br J Nutr. 1993;70:407-19.

44. Bhatnagar AS, Nielsen MK. Lifetime reproductive performance and survival analysis of mice divergently selected for heat loss. J Anim Sci. 2014;92:477-84.

45. García ML, Zbynovska K, Petruska P, Bovdisová I, Kalafová A, Capcarova M. Effect of selection for residual variance of litter size on biochemical parameters in rabbits. In: Proceedings of the 67th annual meeting of the European federation of animal science: 29 Aug-1 Sep 2016. Belfast; 2016.

46. Hill WG, Caballero A. Artificial selection experiments. Annu Rev Ecol Syst. 2000;23:287-310

47. Macé T, González-García E, Pradel J, Parisot S, Carriere F, Douls S, et al. Genetic analysis of robustness in meat sheep through body weight and body condition score changes over time. J Anim Sci. 2018;96:4501-11.

\section{Publisher's Note}

Springer Nature remains neutral with regard to jurisdictional claims in published maps and institutional affiliations.

\footnotetext{
Ready to submit your research? Choose BMC and benefit from:

- fast, convenient online submission

- thorough peer review by experienced researchers in your field

- rapid publication on acceptance

- support for research data, including large and complex data types

- gold Open Access which fosters wider collaboration and increased citations

- maximum visibility for your research: over $100 \mathrm{M}$ website views per year
}

At BMC, research is always in progress.

Learn more biomedcentral.com/submissions 